\title{
Bibliometric Analysis on Research Trends of International Journal of Computers Communications \& Control
}

\author{
X.X. Wang, Z.S. Xu, I. Dzitac
}

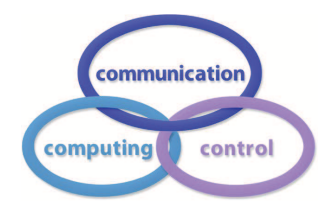

\author{
Xinxin Wang \\ Sichuan University \\ Business School \\ Chengdu 610064, China \\ wangxinxin_cd@163.com \\ Zeshui $\mathrm{Xu}^{*}$ \\ Sichuan University \\ Business School \\ Chengdu 610064, China \\ *Corresponding author: xuzeshui@263.net
}

\section{Ioan Dzitac}

1. Aurel Vlaicu University of Arad

310330 Arad, Elena Dragoi, 2, Romania

ioan.dzitac@uav.ro

2. Agora University of Oradea

410526 Oradea, P-ta Tineretului 8, Romania,

idzitac@univagora.ro

3. University of Craiova

Department of Economic Informatics \& Statistics

Str. A.I. Cuza, nr. 13, Craiova, Romania

\begin{abstract}
International Journal of Computers Communications \& Control $(I J C C C)$ is an international journal in the fields of automation control systems and computer science. According to Web of Science (WoS), the first document of IJCCC was published in 2006. In this paper, we study the research trends of publications in IJCCC by performing bibliometric analysis from 2006 to 2019. 982 publications are selected from WoS after data preprocessing by VOS viewer and CiteSpace. Firstly, fundamental information of publications is explored including the type, the annual trend and the most cited publications in IJCCC. Secondly, characteristics of countries/regions, institutions and authors are presented in terms of evaluation indicators. Next, landscape analysis is conducted to show the development of IJCCC at level of countries/regions, institutions, authors and references, such as co-authorship analysis, bibliographic coupling analysis, co-citation and burst detection analysis, cooccurrence and timeline view analysis. Based on which, discussions about current challenges and possible research trends of $I J C C C$ are provided. Finally, some main findings are summarized. This paper offers a valuable reference for scholars to understand the research trends of IJCCC and grasp hot topics related to relative fields.

Keywords: International Journal of Computers Communications \& Control; bibliometric analysis; Web of Science; landscape analysis; research trends.
\end{abstract}




\section{Introduction}

International Journal of Computers Communications \& Control (IJCCC)is an international journal (ISSN: 1841-9836, e-ISSN 1841-9844) that is directed to the international communities of scientific researchers in computers, communications and control, from the universities, research units and industry. According to the homepage of the journal [32], IJCCC publishes 6 issues per year, and calls for topics which are integrated solutions in computer-based control and communications, computational intelligence methods and soft computing, and advanced decision support systems. The editors-in-chief of IJCCC are professor Ioan DZITAC and professor Florin Gheorghe FILIP, and the journal was founded in 2006, at Agora University, by Ioan DZITAC, Florin Gheorghe FILIP and Misu-Jan MANOLESCU. This journal is a member of the Committee on Publicatin Ethics (COPE) since 2012, and subscribes to the principles of COPE. IJCCC is indexed in Science Citation Index Expanded (SCIE) database from 2006 with an impact factor of 1.585 by Journal Citation Reports (2018), and is also indexed in Scopus database from 2008 with CiteScore (2018) of 1.56. In Web of Science (WoS), IJCCC ranks 38 and 108 among totally 62 and 155 academic journals in the fields of automation \& control systems, and computer science, respectively. In the past decade, IJCCC was nominated by Elservier for Journal Excellence Award - "Scopus Awards Romania 2015" (SNIP2014=1.029), and has been in top 3 of 157 Romanian journals indexed by Scopus (in all fields) and No.1 in Computer Science field by Elservier/Scoupus. Therefore, it is meaningful to study research trends of $I J C C C$ systematically and intuitively by bibliometric methods and visualization tools.

Bibliometrics is an important branch of intelligence science, and bibliometric methods have been effective tools so far to evaluate the merits of a given research direction or a certain journal $[1,21,27]$. On the one hand, the evolution of a research direction could be revealed by bibliometric methods, because bibliometrics is a discipline with the extensive intersection and combination of philology, information science and statistics in a specific area [8]. At present, bibliometrics has been applied to many research fields, such as fuzzy decision making [16], engineering [17], supply chain of renewable energy [2] and sustainable energy [7]. On the other hand, the development trend of a journal could be explored based on bibliometric analysis. For example, productivity and influence could be evaluated by some generally accepted bibliometric indicators, such as total number of publications (TP), total number of citations (TC), average number of citations per publication (AC), and H-index [10]. Bibliometric analysis has attracted more and more scholars to research journals, such as European Journal of Operational Research [14], IEEE Transaction on Fuzzy Systems [28], Technological and Economic Development of Economy [Yu1], Information Sciences [30] and Knowledge-Based Systems [31].

Visualization is one of the most important techniques in bibliometric analysis, because it helps scholars intuitively see the structure and the trend of a research field or a journal [5]. Due to that VoS viewer [22] and CiteSpace [4] have powerful user graphic-interface and mapping visualization capability, they have been the most popular tools to make landscape analysis. VoS viewer could present the structure of publications in the journal by co-authorship analysis, bibliographic coupling analysis and co-occurrence analysis, etc. CiteSpace could grasp hot topics and track development trend of the journal by burst detection analysis and timeline analysis. Until now, VoS viewer and CiteSpace have been widely used in many areas, such as food chemistry [12], computer and information ethics [9], emergency medicine [3], and information literacy assessment [19].

Since WoS is one of the most widely-used databases in academics, and provides many leading journals available and detailed information about publications around the world [6], we collect data using the name of the journal from WoS Core Collection database on September 18, 2019. All publications in IJCCC are exported in plain text format and Comma-Separated Values (CSV) 
format, which contain bibliographic information, keywords information and citation information, etc. As a result, 982 publications are derived in WoS since first publication in 2006. Therefore, we make a bibliometric analysis to study the research trends of IJCCC from 2006 to 2019.

In this paper, the contributions lie in the following aspects:

(1) Fundamental information of publications is provided to describe the inner structure of $I J C C C$, which includes the type, the annual trend and the most cited publications.

(2) Characteristics of publications in IJCCC are presented at the level of countries/regions, institutions and authors by some bibliometric indictors.

(3) Landscape analysis is given by co-authorship analysis, bibliographic coupling analysis, co-citation and burst detection analysis, co-occurrence analysis and timeline view analysis.

(4) The current challenges and research trends of IJCCC are discussed according to the above-mentioned analysis.

The rest of this paper is organized as follows: Section 2 illustrates fundamental information. In Section 3, the characteristics of publications are given at level of countries/regions, institutions and authors. Section 4 makes landscape analysis. In Section 5, some discussions are provided about current challenges and research trends in IJCCC. Section 6 ends the paper with some conclusions.

\section{Fundamental information of publications in IJCCC}

In this section, we introduce the fundamental information of publications in $I J C C C$ from 2006 to 2019, including the type of publications, the annual trend of publications, and the most cited publications in $I J C C C$.

\subsection{Type of publications in IJCCC}

Automation control systems and computer science are research directions of publications in $I J C C C$. In WoS, the publications in IJCCC are dived into six types, which are articles, proceeding papers, editorial materials, biographic items, corrections and reviews in order. Figure 1 shows the information in detail.

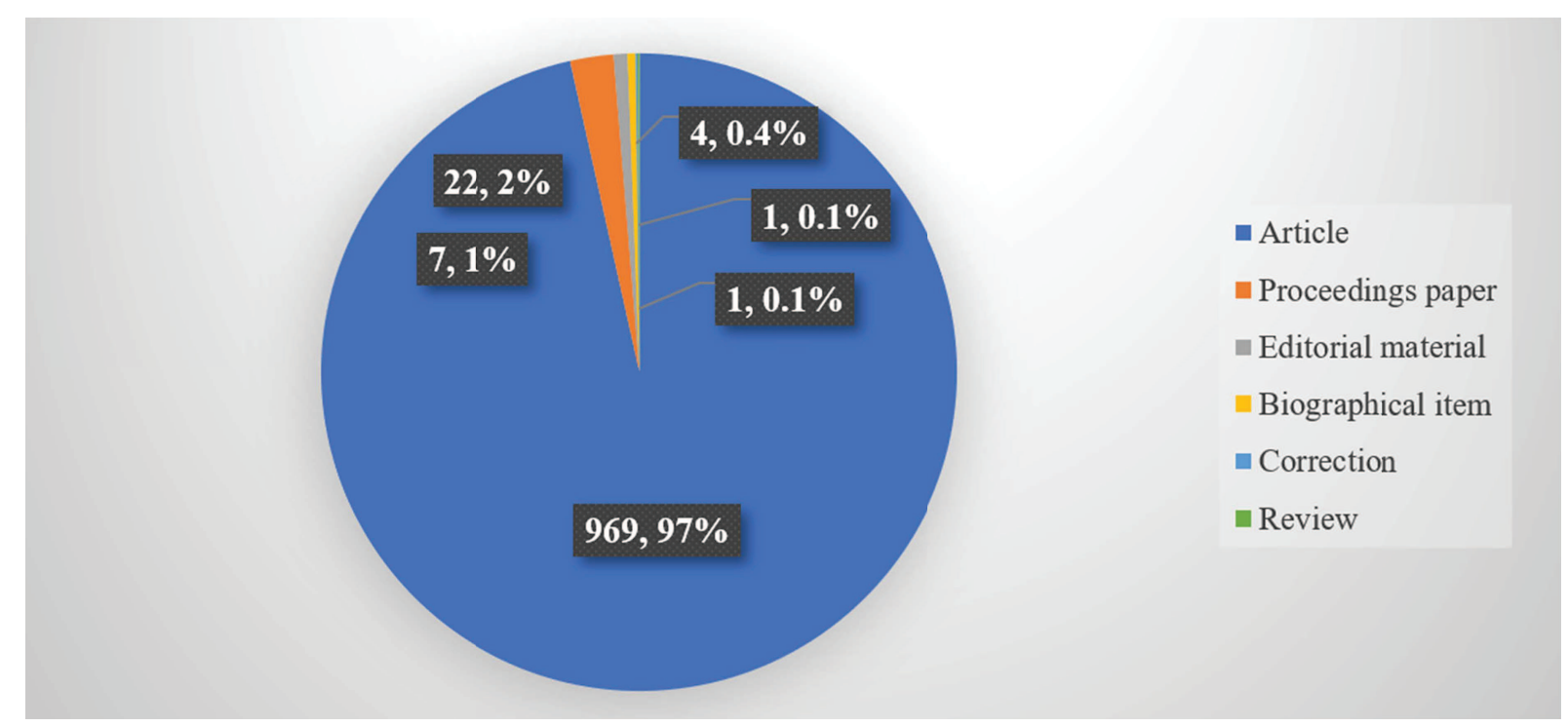

Figure 1: The type of publications in IJCCC 
Table 1: Annual information of publications in IJCCC from 2006 to 2019

\begin{tabular}{|l|l|l|l|l|}
\hline Year & TP & TC & AC & H-index \\
\hline 2006 & 85 & 88 & 1.04 & 5 \\
\hline 2007 & 35 & 304 & 8.69 & 11 \\
\hline 2008 & $\mathbf{1 2 5}$ & $\mathbf{7 0 1}$ & 5.61 & $\mathbf{1 4}$ \\
\hline 2009 & 41 & 396 & $\mathbf{9 . 6 6}$ & 10 \\
\hline 2010 & 92 & 436 & 4.74 & 10 \\
\hline 2011 & 65 & 329 & 5.06 & 9 \\
\hline 2012 & 85 & 341 & 4.01 & 9 \\
\hline 2013 & 85 & 433 & 5.09 & 11 \\
\hline 2014 & 73 & 261 & 3.58 & 9 \\
\hline 2015 & 75 & 350 & 4.67 & 9 \\
\hline 2016 & 64 & 235 & 3.67 & 7 \\
\hline 2017 & 59 & 153 & 2.59 & 6 \\
\hline 2018 & 59 & 116 & 1.97 & 4 \\
\hline 2019 & 39 & 28 & 0.72 & 3 \\
\hline
\end{tabular}

Obviously, articles are the most type of publications in $I J C C C$ with the number of 969, which occupies a comparatively great proportion (97\%) of all documents. The types are followed by proceeding papers $(22,2 \%)$, editorial materials $(7,1 \%)$, biographic items $(4,0.4 \%)$, corrections $(1,0.1 \%)$ and reviews $(1,0.1 \%)$.

\subsection{Annual trend of publications in IJCCC}

In order to describe the trend of publications in IJCCC from 2006 to 2019, Table 1 lists the annual information in terms of some evaluation indicators, i.e., TP, TC, AC and H-index.

Noted that the maximum value under each indicator is highlighted in bold. Obviously, 2008 is the most prominent year because of the highest TP (125), the highest TC (701) and the highest H-index (14). Besides, the publications in 2009 have the highest AC (9.66), followed by 2007 (8.69) and 2008 (5.61).

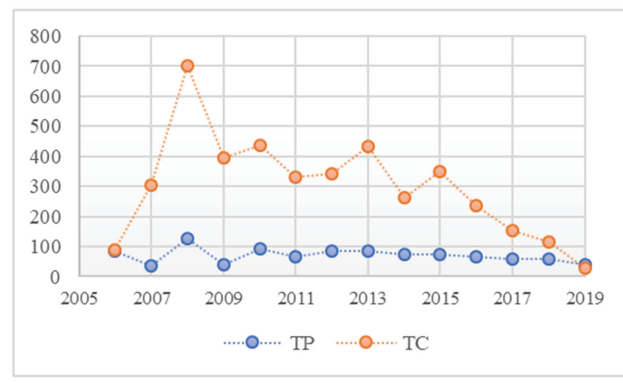

(a)

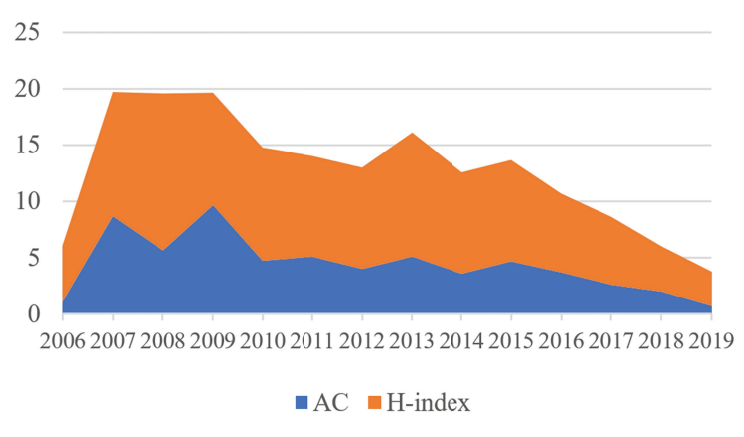

(b)

Figure 2: The annual trends of publications in IJCCC: (a) The annual distributions of TP and TC; (b) The annual distributions of $\mathrm{AC}$ and $\mathrm{H}$-index

Figure 2 shows the annual trends of publications in $I J C C C$ with respect to TP, TC, AC and H-index, respectively. In Figure 2 (a), the distribution of TP shows a steady trend in the last 
Table 2: The information of top 10 cited publications in IJCCC

\begin{tabular}{|l|l|l|l|l|l|l|}
\hline Rank & Title (Type) & Author & Country & Year & Citation & AC \\
\hline 1 & $\begin{array}{l}\text { Spiking Neural P Systems with Anti-Spikes } \\
\text { (Article) }\end{array}$ & Pan et al. & China & 2009 & 99 & 9 \\
\hline 2 & $\begin{array}{l}\text { Tissue P Systems with Cell Division (Arti- } \\
\text { cle) }\end{array}$ & $\begin{array}{l}\text { Paun et } \\
\text { al. }\end{array}$ & Romania & 2008 & 71 & 5.92 \\
\hline 3 & $\begin{array}{l}\text { Generalized Ordered Propositions Fusion } \\
\text { Based on Belief Entropy (Article) }\end{array}$ & Li et al. & China & 2018 & 60 & 30 \\
\hline 4 & $\begin{array}{l}\text { Extended EDAS Method for Fuzzy Multi- } \\
\text { criteria Decision-making: An Application } \\
\text { to Supplier Selection (Article) }\end{array}$ & $\begin{array}{l}\text { Keshavarz } \\
\text { Ghorabaee } \\
\text { et al. }\end{array}$ & Lithuania & 2016 & 54 & 13.5 \\
\hline 5 & $\begin{array}{l}\text { Determining Basic Probability Assignment } \\
\text { Based on the Improved Similarity Measures } \\
\text { of Generalized Fuzzy Numbers (Article) }\end{array}$ & $\begin{array}{l}\text { Jiang et } \\
\text { al. }\end{array}$ & China & 2015 & 52 & 10.4 \\
\hline 6 & $\begin{array}{l}\text { Ant Systems \& Local Search Optimization } \\
\text { for Flexible Job Shop Scheduling Produc- } \\
\text { tion (Article) }\end{array}$ & $\begin{array}{l}\text { Liouane } \\
\text { et al. }\end{array}$ & Tunisia & 2007 & 49 & 3.77 \\
\hline 7 & $\begin{array}{l}\text { A Hybrid Model Based on Fuzzy AHP and } \\
\text { Fuzzy WASPAS for Construction Site Se- } \\
\text { lection (Article) }\end{array}$ & $\begin{array}{l}\text { Turskis } \\
\text { et al. }\end{array}$ & Lithuania & 2015 & 48 & 9.6 \\
\hline 8 & $\begin{array}{l}\text { Fuzzy Logic Control System Stability Anal- } \\
\text { ysis Based on Lyapunov's Direct Method } \\
\text { (Article) }\end{array}$ & $\begin{array}{l}\text { Precup et } \\
\text { al. }\end{array}$ & Romania & 2009 & 47 & 4.27 \\
\hline 9 & $\begin{array}{l}\text { EECDA: Energy Efficient Clustering and } \\
\text { Data Aggregation Protocol for Heteroge- } \\
\text { neous Wireless Sensor Networks (Article) }\end{array}$ & $\begin{array}{l}\text { Kumar et } \\
\text { al. }\end{array}$ & India & 2011 & 44 & 4.89 \\
\hline $\begin{array}{l}\text { Computing Nash Equilibria by Means of } \\
\text { Evolutionary Computation (Article) }\end{array}$ & $\begin{array}{l}\text { Lung et } \\
\text { al. }\end{array}$ & Romania & 2008 & 41 & 3.42 \\
\hline
\end{tabular}

decade, while the trend of TC increases from 2006 to 2008, and has a certain fluctuation between 2009 and 2015, and has been decreasing from 2016 to 2019. Noted that it does not imply that no excellent contributions appeared since 2016, but rather that it always needs time for publications to be widely recognized and cited [18]. In Figure 2 (b), there are two peaks about AC, and one is in 2009, the other is in 2007. The trend of AC is steady from 2010 to 2016. In terms of H-index of publications, the highest H-index is 14 in 2008, followed by 11 in 2007 and 2013, respectively. The distribution of H-index shows a steady trend from 2007 to 2015.

\subsection{The most cited publications in IJCCC}

There are some highly publications in IJCCC since 2006, which have impact on the research field. Table 2 lists the information of top 10 cited publications in detail, including title, type, author, country, year, citation and AC.

The top 10 cited publications in IJCCC are all articles from China (3), Romania (3), Lithuania (2), Tunisia (1) and India (1). The publications by Pan et al. in 2009 and by Li et al. in 2018 have the highest citation (99), and the highest AC (30), respectively. The research content of the top 10 cited publications mainly contains $\mathrm{P}$ systems, information fusion and fuzzy theory. Specially, half of them made research based on fuzzy information, and applied to belief entropy [15], decision making [13], similarity measures [11], AHP and WASPAS [23], and logic control system [20], which indicates that fuzzy theory has been very popular and effective in both theoretical research $[24,26]$ and practical application [25]. 
Table 3: The top 10 prolific countries/regions of publications in IJCCC

\begin{tabular}{|l|l|l|l|l|l|l|l|l|l|l|}
\hline Rank & Country & TP & TC & AC & $\geq 50$ & $\geq 30$ & $\geq 20$ & $\geq 10$ & $\%$ TP & $\begin{array}{l}\text { H- } \\
\text { index }\end{array}$ \\
\hline 1 & Romania & $\mathbf{3 5 4}$ & $\mathbf{1 5 3 1}$ & 4.32 & 2 & $\mathbf{1 0}$ & $\mathbf{1 2}$ & $\mathbf{3 9}$ & $\mathbf{3 6 . 0 5 \%}$ & $\mathbf{1 7}$ \\
\hline 2 & China & 199 & 889 & 4.47 & $\mathbf{3}$ & 4 & 8 & 24 & $20.26 \%$ & 13 \\
\hline 3 & India & 52 & 234 & 4.5 & 0 & 2 & 2 & 9 & $5.30 \%$ & 9 \\
\hline 4 & France & 49 & 304 & 6.2 & 0 & 1 & 3 & 11 & $4.99 \%$ & 10 \\
\hline 5 & USA & 49 & 200 & 4.08 & 0 & 0 & 2 & 3 & $4.99 \%$ & 7 \\
\hline 6 & Chile & 38 & 116 & 3.05 & 0 & 0 & 0 & 3 & $3.87 \%$ & 6 \\
\hline 7 & Spain & 33 & 357 & $\mathbf{1 0 . 0 8}$ & 2 & 3 & 4 & 8 & $3.36 \%$ & 9 \\
\hline 8 & Serbia & 30 & 135 & 4.5 & 0 & 1 & 1 & 2 & $3.05 \%$ & 6 \\
\hline 9 & South Korea & 29 & 46 & 1.59 & 0 & 0 & 0 & 1 & $2.95 \%$ & 3 \\
\hline 10 & Tunisia & 23 & 197 & 8.57 & 0 & 1 & 2 & 7 & $2.34 \%$ & 4 \\
\hline
\end{tabular}

\section{Characteristics of countries/regions, institutions, and authors}

Author(s) and the corresponding incidental information are important parts of each publication, and we further analyze the characteristics of publications in IJCCC at level of countries/regions, institutions, and authors, respectively.

\subsection{Characteristic at level of countries/regions}

So far, 71 countries/regions have published documents in IJCCC since 2006, and the distribution around the world in detail is shown in Figure 3.

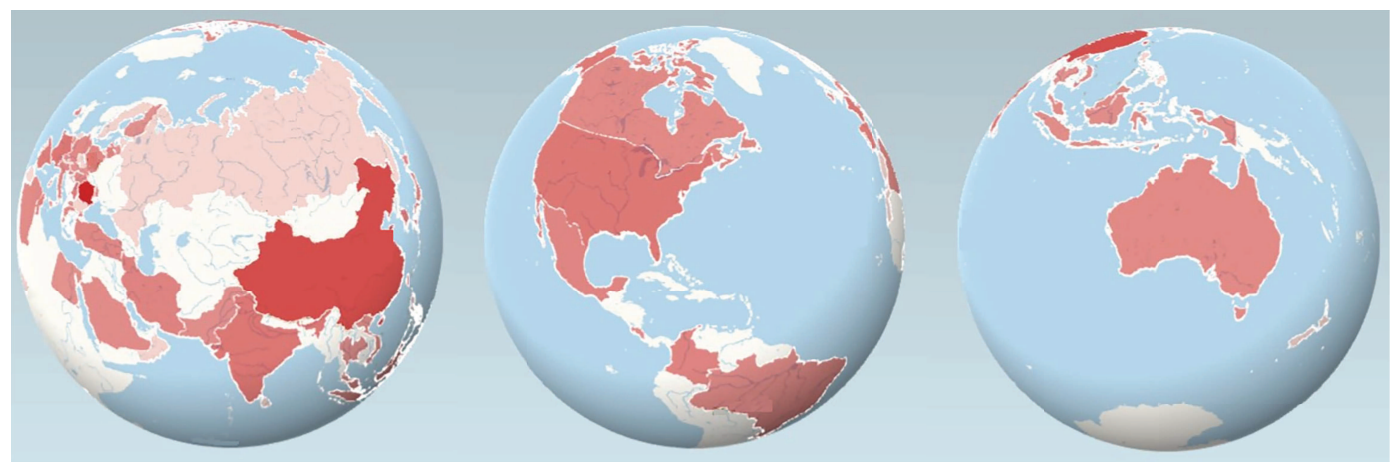

Figure 3: Countries/regions' distribution of publications in IJCCC

It is noted that the redder the color is, the more publications the country/region has. As we can see, countries/regions cover five continents, especially in North America, Australia and Europe. Besides, the most publications are mainly from East Europe, East Asia and South Asia. Table 3 lists the top 10 prolific countries/regions of publications in IJCCC, considering evaluation indicators, i.e., TP, TC, AC, \% TP, H-index and the numbers of citations no less than $50 / 30 / 20 / 10$.

In Table 3, the maximum value under each indicator is also highlighted in bold. Romania is very prominent according to $\mathrm{TP}, \mathrm{TC}, \% \mathrm{TP}$ and $\mathrm{H}$-index, which indicates that Romania makes a great contribution to IJCCC. Spain has the highest AC (10.08), which denotes that the publications from Spain have received the highest recognition, followed by Tunisia (8.57), France (6.2) and India (4.5). Moreover, China has the most highly cited publications in IJCCC, because it ranks the first in terms of the number of citations no less than 50 . 


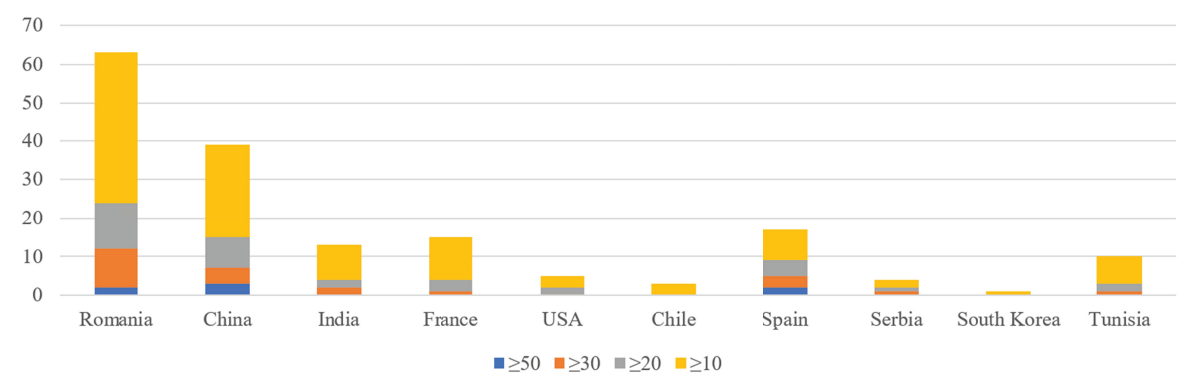

Figure 4: The number of citations no less than 50/30/20/10 in the top 10 prolific countries/regions

According to the number of citations no less than 50/30/20/10, Figure 4 shows the situation of the top 10 prolific countries/regions. The publications from three countries have been cited no less than 50, which are China, Romania and Spain, while Chile and South Korea do not have publication that is cited more than 20. In addition, Romania has the most publications that are cited no less than 30/20/10, followed by China. Overall, Romania is the most influential country in terms of publications in $I J C C C$, followed by China, Spain and France.

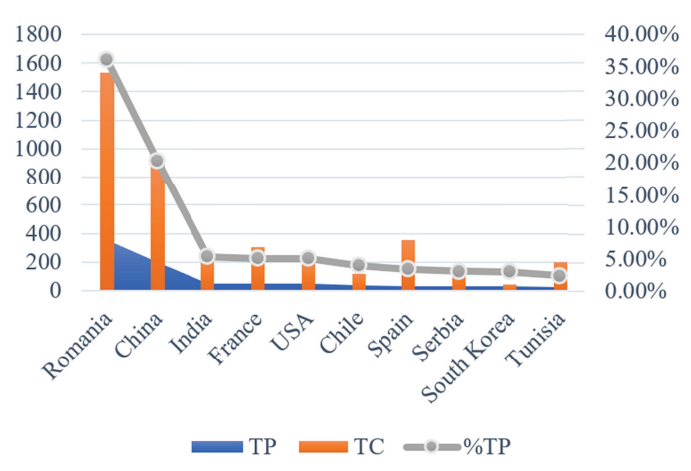

(a)

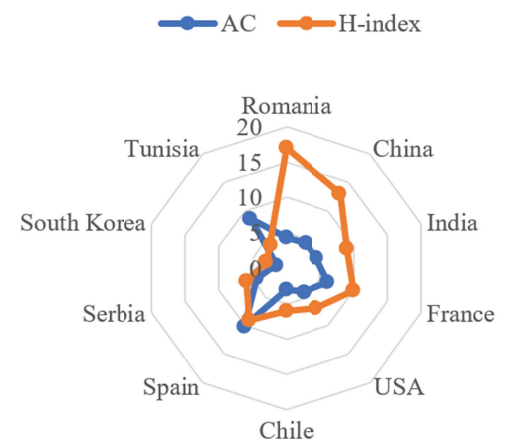

(b)

Figure 5: The situation of TP, TC, \% TP, AC and H-index in the top 10 prolific countries/regions: (a) The situation of TP, TC and \% TP; (b) The situation of $\mathrm{AC}$ and H-index

In terms of TP, TC, \% TP, AC and H-index, Figure 5 shows the situation of the top 10 prolific countries/regions. In Figure 5 (a), more than half of the total publications are from Romania and China. Although Spain is the seventh for TP, it ranks the third as far as TC is concerned. In Figure 5 (b), the radar map of AC and H-index is drawn. Spain does well in AC, and Romania is prominent in $\mathrm{H}$-index. The gap of H-index is wider than the gap of AC among the top 10 prolific countries/regions.

\subsection{Characteristic at level of institutions}

In the following, we investigate the prolific institutions among totally 763 institutions in IJCCC. Table 4 lists the top 10 prolific institutions of publications in detail.

In Table 4, top 9 prolific institutions are from Romania, and the rest is from China, which indicates that the institutions in Romania have strong interest in IJCCC. BABES BOLYAI UNIVERSITY is the most prolific institution considering TP, followed by UNIVERSITY OF ORADEA and LUCIAN BLAGA UNIVERSITY OF SIBIU. According to TC, AC and H-index, 
Table 4: The top 10 prolific institutions of publications in $I J C C C$

\begin{tabular}{|l|l|l|l|l|l|l|}
\hline Rank & Institution & Country & TP & TC & AC & H-index \\
\hline 1 & BABES BOLYAI UNIVERSITY & Romania & $\mathbf{4 9}$ & 151 & 3.08 & 7 \\
\hline 2 & $\begin{array}{l}\text { UNIVERSITY OF ORADEA } \\
\text { LUCIAN BLAGA UNIVERSITY OF } \\
\text { SIBIU }\end{array}$ & Romania & 47 & 215 & 4.57 & 8 \\
\hline 4 & $\begin{array}{l}\text { AUREL VLAICU UNIVERSITY OF } \\
\text { ARAD }\end{array}$ & Romania & 35 & 232 & 6.63 & 8 \\
\hline 5 & $\begin{array}{l}\text { ROMANIAN ACADEMY OF SCIENCES } \\
\text { TECHNICAL UNIVERSITY OF CLUJ } \\
\text { NAPOCA }\end{array}$ & Romania & 31 & $\mathbf{4 0 4}$ & $\mathbf{1 3 . 0 3}$ & $\mathbf{1 0}$ \\
\hline 6 & $\begin{array}{l}\text { POLYTECHNIC UNIVERSITY OF } \\
\text { BUCHAREST Romania }\end{array}$ & 23 & 51 & 2.22 & 5 \\
\hline 8 & $\begin{array}{l}\text { TRANSYLVANIA UNIVERSITY OF } \\
\text { BRASOV }\end{array}$ & Romania & 23 & 52 & 2.26 & 4 \\
\hline 9 & $\begin{array}{l}\text { AGORA UNIV ORADEA } \\
\text { BEIJING JIAOTONG UNIVERSITY }\end{array}$ & Chinana & 21 & 110 & 5.24 & 7 \\
\hline 10 & & & 49 & 2.45 & 4 \\
\hline
\end{tabular}

ROMANIAN ACADEMY OF SCIENCES ranks the first, which represents that the publications of the institution in $I J C C C$ have won wide recognition in the field of research.

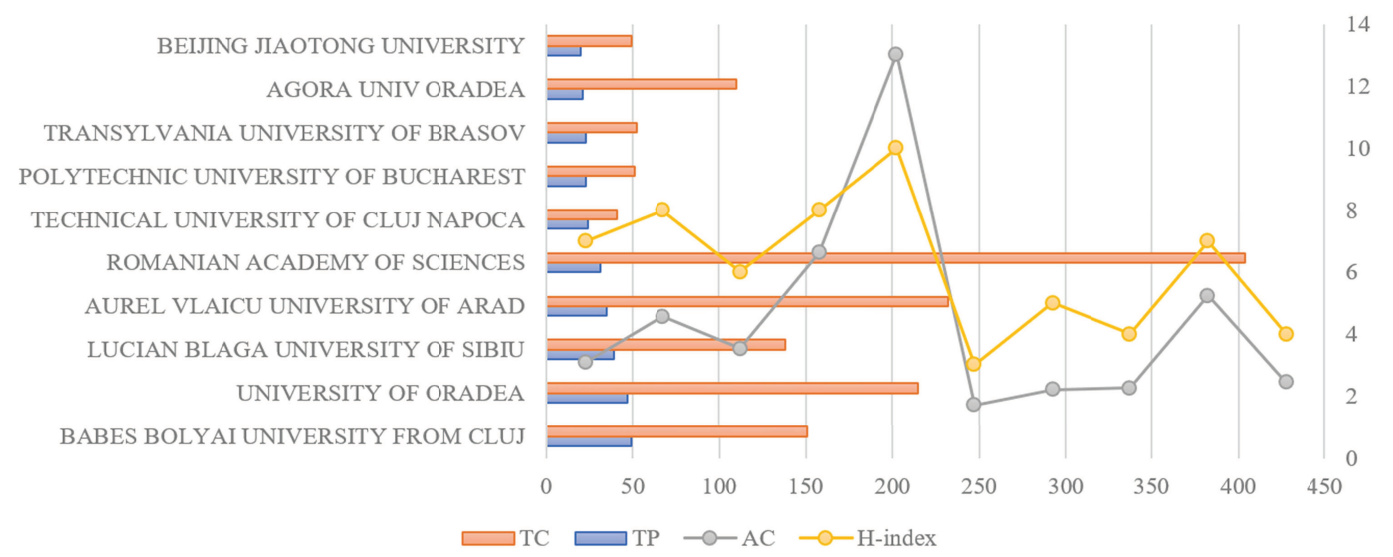

Figure 6: The situation of TC, TP, AC and H-index in the top 10 prolific institutions

Figure 6 depicts the situation of TC, TP, AC and H-index in the top 10 prolific institutions. The difference of TC is more significant than the difference of TP among the top 10 prolific institutions, and ROMANIAN ACADEMY OF SCIENCES performs well in terms of TC, followed by AUREL VLAICU UNIVERSITY OF ARAD and UNIVERSITY OF ORADEA. In addition, the range of $\mathrm{AC}$ is bigger than the range of H-index, and the trends of $\mathrm{AC}$ and $\mathrm{H}$-index are basically consistent among the top 10 prolific institutions in IJCCC.

\subsection{Characteristic at level of authors}

At present, 2,049 authors around the world have publication(s) in IJCCC, and Table 5 lists the top 10 prolific authors of publications in detail.

In the top 10 prolific authors of publications in $I J C C C$, four authors from Romania, and two authors from Chile, and Colombia, France, USA, and Tunisia have one author, respectively. According to TP, TC and H-index, DZITAC I. (Romania) is the leading author, and BORNE P. 
Table 5: The top 10 prolific authors of publications in IJCCC

\begin{tabular}{|l|l|l|l|l|l|l|}
\hline Rank & Author & Country & TP & TC & AC & H-index \\
\hline 1 & DZITAC I. & Romania & $\mathbf{2 3}$ & $\mathbf{1 4 9}$ & 6.48 & $\mathbf{7}$ \\
\hline 2 & DONOSO Y. & Colombia & 16 & 41 & 2.56 & 4 \\
\hline 3 & BORNE P. & France & 12 & 136 & $\mathbf{1 1 . 3 3}$ & $\mathbf{7}$ \\
\hline 4 & DUMITRESCU D. & Romania & 11 & 59 & 5.36 & 3 \\
\hline 5 & DZITAC S. & Romania & 11 & 62 & 5.64 & 5 \\
\hline 6 & ANDONIE R. & USA & 10 & 36 & 3.6 & 3 \\
\hline 7 & LEFRANC G. & Chile & 9 & 17 & 1.89 & 3 \\
\hline 8 & MANOLESCU M.J. & Romania & 9 & 62 & 6.89 & 3 \\
\hline 9 & BENREJEB M. & Tunisia & 8 & 63 & 7.88 & 4 \\
\hline 10 & CUBILLOS C. & Chile & 8 & 16 & 2 & 2 \\
\hline
\end{tabular}

(France) ranks the first in terms of $\mathrm{AC}$ and H-index.

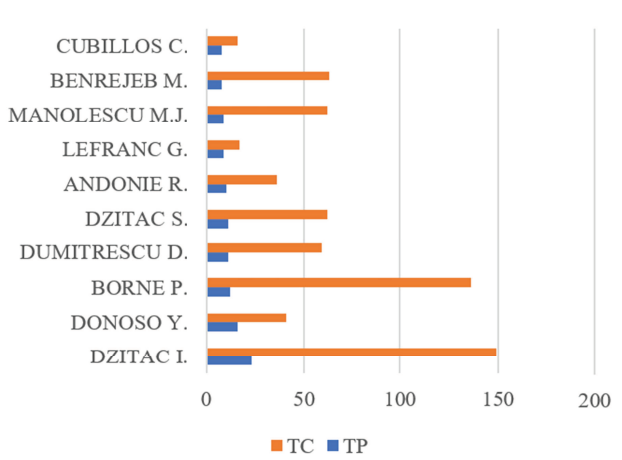

(a)

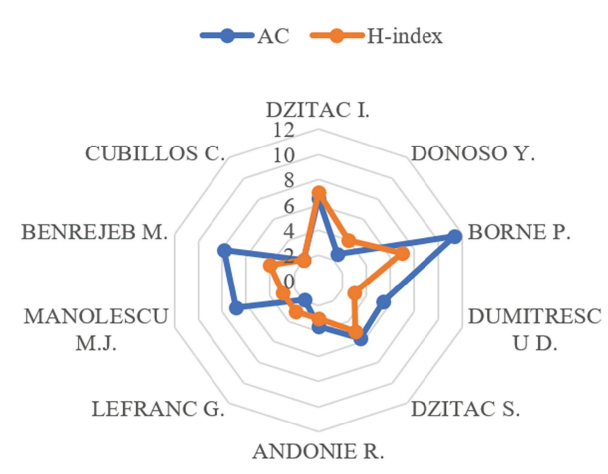

(b)

Figure 7: The situation of TC, TP, AC and H-index in the top 10 prolific authors: (a) The situation of TC and TP (b) The situation of AC and H-index

Figure 7 shows the situation of the top 10 prolific authors with respect to TC, TP, AC and H-index. In Figure 7 (a), there is a greater gap with TC compared with TP among the top 10 prolific authors, and DZITAC I. (Romania) ranks the first according to TC, followed by BORNE P. (France) and BENREJEB M. (Tunisia). In Figure 7 (b), BORNE P. (France), BENREJEB M. (Tunisia) and MANOLESCU M.J. (Romania) are prominent in order according to AC. DZITAC I. (Romania) and BORNE P. (France) are leading authors in terms of H-index. Moreover, the difference of $\mathrm{AC}$ is bigger than the difference of $\mathrm{H}$-index among the top 10 prolific authors of publications in $I J C C C$.

\section{Landscape analysis}

With the help of VoS viewer and CiteSpace, we make landscape analysis of publications in IJCCC from 2006 to 2019. Specifically, we do bibliometric analysis from four aspects, which are co-authorship analysis, bibliographic coupling analysis, co-citation and burst detection analysis, and co-occurrence and timeline view analysis, respectively. 


\subsection{Co-authorship analysis}

In order to reflect the collaboration relationship clearly of publications in $I J C C C$ during the whole time period, overlay visualization of co-authorship is described at level of countries/regions, institutions and authors by VoS viewer. It is noted that a node represents a country/region/institution/author, and the size of the node means the number of cooperation in overlay visualization. A link between two nodes indicates a collaboration relationship, and the thicker the link is, the more cooperation they have. The color of a node or a link mans the overlay time of co-authorship about countries/regions, institutions and authors.

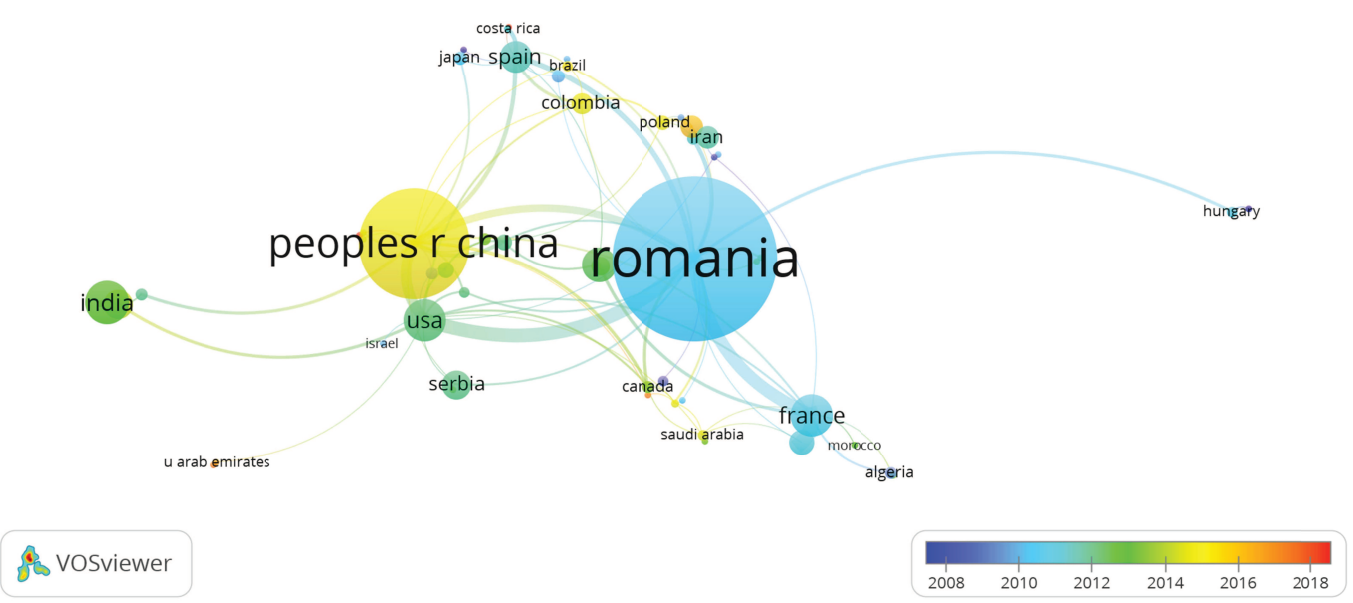

Figure 8: Overlay visualization of co-authorship at level of countries/regions in IJCCC

Figure 8 shows the overlay visualization about countries/regions of publications in IJCCC, where 71 countries/regions are selected when the minimum number of publications is set as 1 . Overall, Romania and China are highlight, which indicates that they have many co-authorship publications in IJCCC from 2010 to 2012, and from 2014 to 2016, respectively. During each interval of timeline, the most prominent countries are Algeria, Romania, India and China in order. In addition, Romania and France have more cooperation between 2010 and 2012, while Romania and USA have closer cooperation between 2012 and 2014.

According to the institutions of publications in IJCCC, Figure 9 shows the overlay visualization of co-authorship where 50 institutions are selected among totally 812 institutions set the minimum number of publications as 5. UNIVERSITY OF ORADEA (Romania) and LUCIAN BLAGA UNIVERSITY OF SIBIU (Romania) are prominent in co-authorship from 2010 to 2012. VILNIUS GEDIMINAS TECHNICAL UNIVERSITY (Lithuania) and UNIVERSITY OF ELECTRONIC SCIENCE AND TECHNOLOGY OF CHINA (China) have more co-authorship publications in $I J C C C$ in recent years.

Similarly, Figure 10 describes the overlay visualization of authors' co-authorship in IJCCC, where 338 authors are selected among totally 2,250 authors set the minimum number of publications as 2. As we can see, the authors between 2014 and 2018 have more co-authorship publications in IJCCC than the authors between 2008 and 2014. Besides, DONOSO Y. (Colombia) and DZITAC I. (Romania) perform better about co-authorship from 2014 to 2016. 


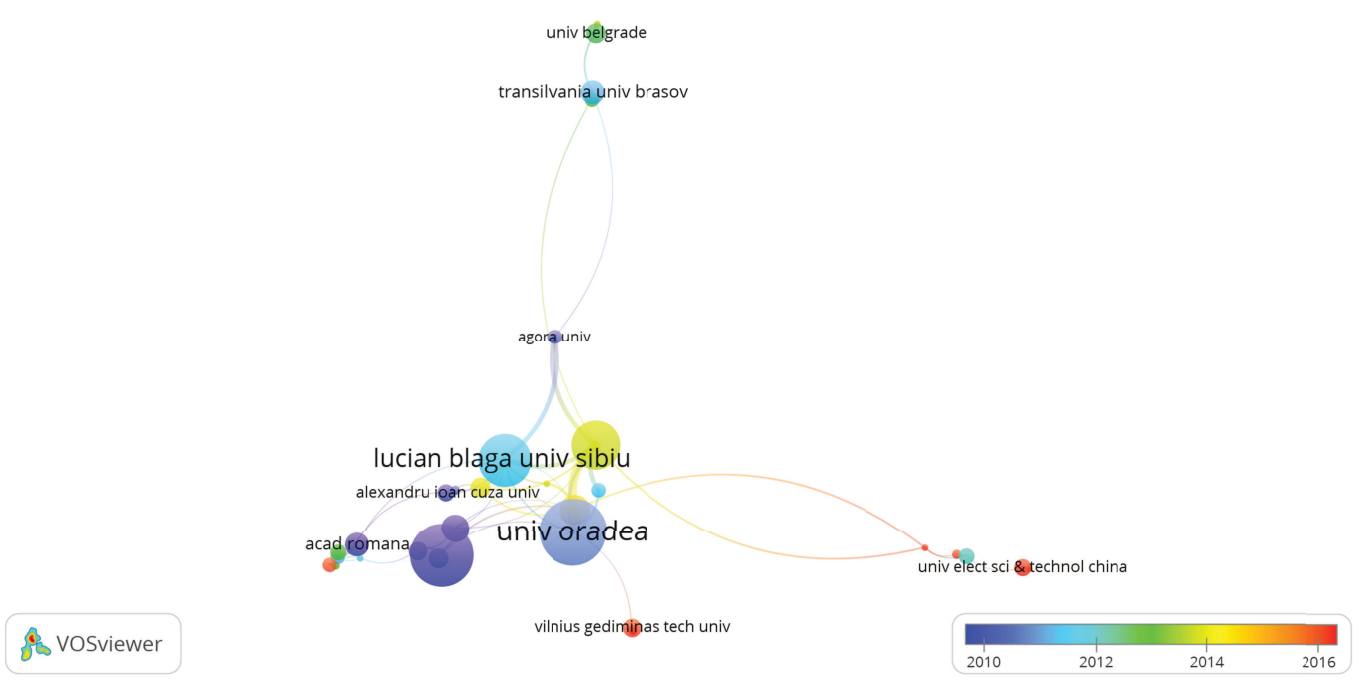

Figure 9: Overlay visualization of co-authorship at level of institutions in IJCCC

\subsection{Bibliographic coupling analysis}

In order to describe a similarity relationship of relative information in IJCCC from 2006 to 2019, we make density visualization of bibliographic coupling analysis by VoS viewer in terms of publications, authors, institutions and countries/regions. The redder the publication/author/institution/country/region is in the map of density visualization, the higher the coupling degree is, which indicates that the closer the subject content and professional nature of the two publications/authors/institutions/countries/regions are.

Figure 11 depicts the density visualization of bibliographic coupling analysis with respect to publications and authors in IJCCC. In Figure 11 (a), 118 publications are selected among totally 982 publications when the minimum number of publications is set as 10. There are two hotspots, and the highest coupling degree publication is Pan (2009), followed by Li (2018) and Keshavarz Ghorabaee (2016). In Figure 11 (b), we set the minimum number of publications as 5, and 29 authors meet the threshold among totally 2,250 authors. The number of authors is more than publications in terms of hotspot, and DONOSO Y. (Colombia) and DZITAC I. (Romania) are most prominent in bibliographic coupling.

According to institutions and countries/regions, Figure 12 shows the density visualization of bibliographic coupling analysis. When the minimum number of publications is set as 5,50 institutions meet the threshold among totally 812 institutions, and 33 countries/regions meet the threshold among totally 71 countries/regions. In Figure 12 (a), UNIVERSITY OF ORADEA (Romania) is the most prominent institution and has the high connection degree with other institutions. In Figure 12 (b), Romania has the highest coupling degree, which represents that scholars prefer to cite publications in IJCCC from Romania, followed by China and India.

\subsection{Co-citation and burst detection analysis}

Considering the cited authors/journals/references in $I J C C C$, we make co-citation analysis by CiteSpace and VoS viewer. In the co-citation network by CiteSpace, a node indicates an author/journal/reference, and the size of the node means the number of citations with which the author/journal/reference is cited. A link between two nodes represents a co-citation relationship. The thicker the link is, the more citations the author/journal/reference has, and the top of them 


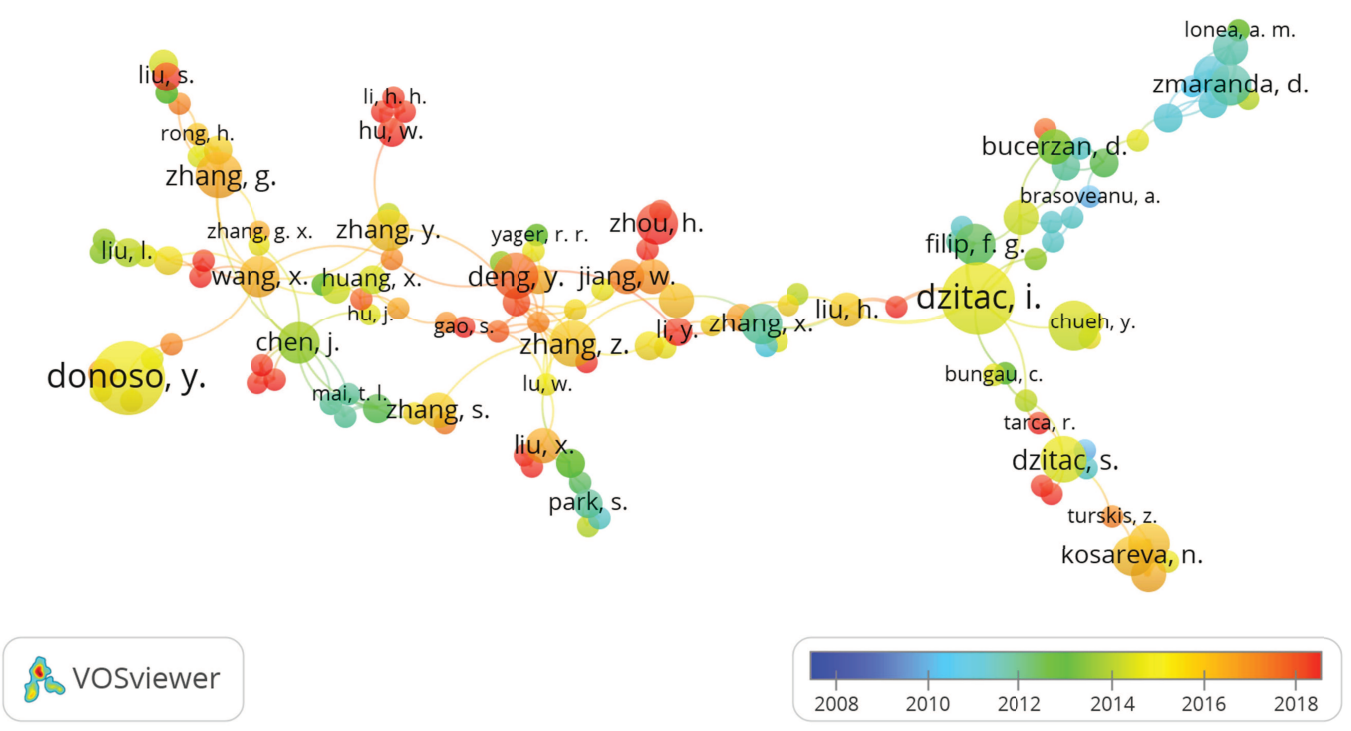

Figure 10: Overlay visualization of co-authorship at level of authors in IJCCC

are labeled in the networks.

According to the cited authors and the cited journals, Figure 13 shows the co-citation networks of publications in IJCCC by CiteSpace. There are 12,122 nodes and 19,910 edges about authors in Figure 13 (a), and 9,216 nodes and 30,760 edges about journals in Figure 13 (b). As we can see, high cited authors are more dispersive in their cooperative relationship, while high cited journals are relative concentration. Table 6 and Table 7 list the top 12 cited authors/journals with strongest citation bursts from 2006 to 2019, respectively.

In Table 6, DZITAC I. ranks the first with the maximum burst strength of 3.9746. The publications by WANG J. and ZHANG G. X. have made a far-reaching impact, because they own the longest citation burst duration with five years from 2015 to 2019. The citation bursts of six authors (DZITAC I., WANG J., WANG T., ZHANG G. X., DEMPSTER A. P. and CHEN

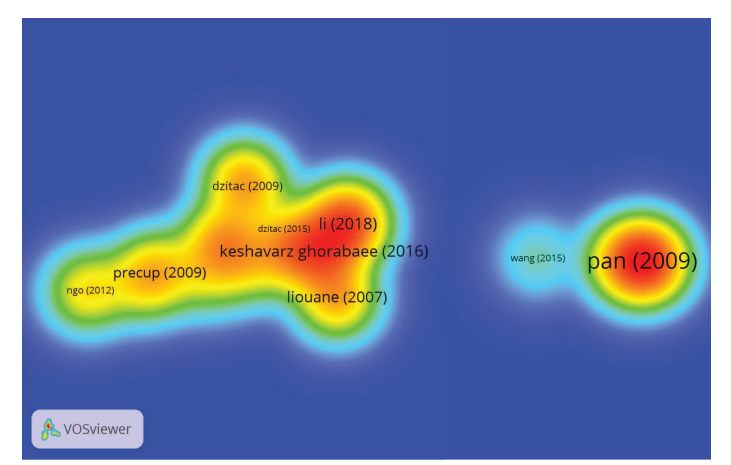

(a)

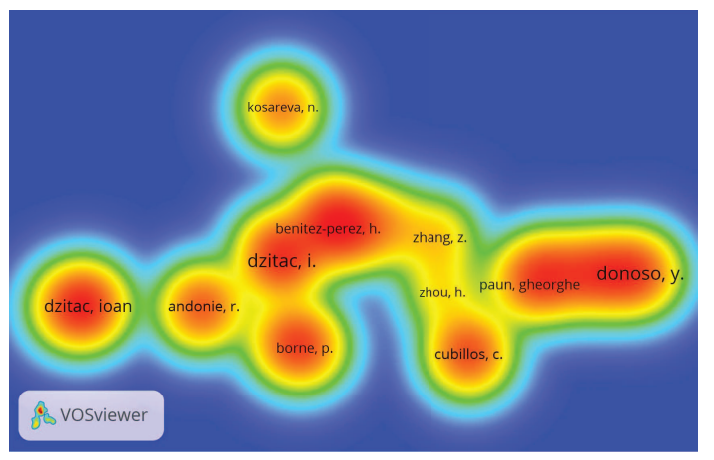

(b)

Figure 11: Density visualization of bibliographic coupling analysis at level of publications and authors in IJCCC: (a) Publications' bibliographic coupling analysis; (b) Authors' bibliographic coupling analysis 
Bibliometric Analysis on Research Trends of

Table 6: The top 12 cited authors with the strongest citation bursts from 2006 to 2019

\begin{tabular}{|c|c|c|c|c|c|c|}
\hline Rank & Cited Authors & Year & Strength & Begin & End & 2006-2019 \\
\hline 1 & DZITAC I & 2006 & 3.9746 & 2017 & 2019 & \\
\hline 2 & NADABAN S & 2006 & 3.7872 & 2015 & 2017 & \\
\hline 3 & AKYILDIZ IF & 2006 & 3.7701 & 2012 & 2015 & \\
\hline 4 & WANG J & 2006 & 3.7064 & 2015 & 2019 & \\
\hline 5 & WANG T & 2006 & 3.4668 & 2017 & 2019 & \\
\hline 6 & LI M & 2006 & 3.4269 & 2016 & 2017 & \\
\hline 7 & ZHANG GX & 2006 & 3.4152 & 2015 & 2019 & \\
\hline 8 & CHEN SM & 2006 & 3.3259 & 2014 & 2015 & \\
\hline 9 & CIOBANU G & 2006 & 3.1619 & 2009 & 2010 & \\
\hline 10 & DEMPSTER AP & 2006 & 3.0792 & 2017 & 2019 & \\
\hline 11 & CHEN X & 2006 & 3.0752 & 2016 & 2019 & \\
\hline 12 & BARBAT BE & 2006 & 3.0331 & 2008 & 2010 & \\
\hline
\end{tabular}




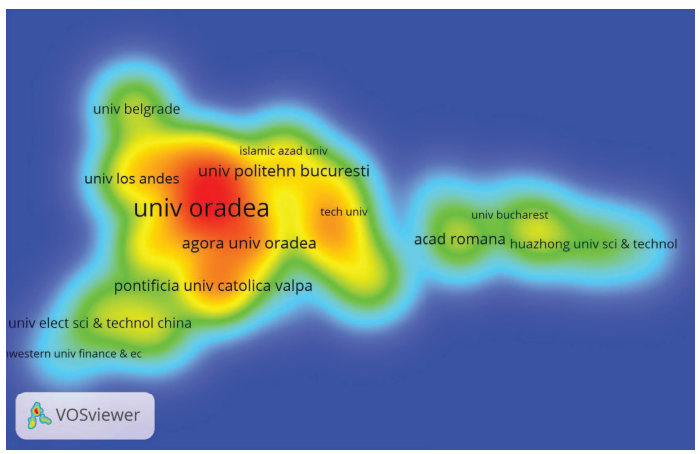

(a)

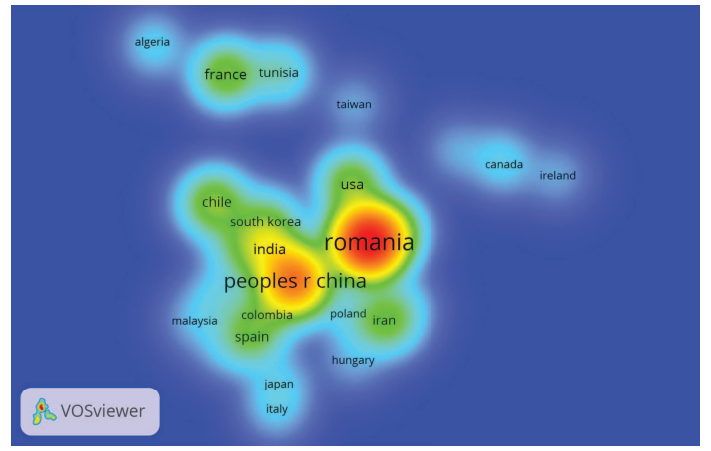

(b)

Figure 12: Density visualization of bibliographic coupling analysis at level of institutions and countries/regions in IJCCC: (a) Institutions' bibliographic coupling analysis;(b) Countries/regions' bibliographic coupling analysis

X.) are close to 2019, which indicates that their work may have formed a popular topic at present.

In Table 7, LECT. NOTES. COMPUTER, which is an important branch about computer sciences in Springer, has the strongest strength with the value of 8.6363, followed by $M E M$ BRANE COMPUTING I. and IEEE ACM. T. NETWORK. The citation burst of THEOR. COMPUT. SCI. has the longest duration with six years from 2006 to 2011. In addition, LECT. NOTES. COMPUTER and THEOR. COMPUT. SCI. began earlier from 2006, which illustrates that the publications in IJCCC cited them earlier and explosively.

Considering the cited references in $I J C C C$, Figure 14 shows the co-citation density visualization by VoS viewer. There are totally 16,675 cited references in IJCCC, and two cited references are very prominent, which are PAUN G. (2000) and DZITAC I. (2009). Table 8 lists the detailed information of two references with the strongest citation bursts from 2006 to 2019.

There are only two cited references with strongest citation bursts, which both began from 2009 and ended to 2010. To be specific, PAUN G. (2000) has the strongest strength with the value of 7.6022 , followed by DZITAC I. (2009) with the value of 5.8144 .

\subsection{Co-occurrence and timeline view analysis}

Keywords are important information to understand the knowledge structure and the research trend in the journal. In the following, we make a keyword co-occurrence analysis of publications in IJCCC by VoS viewer. There are 3,842 keywords of publications in IJCCC from 2006 to 2019, and 98 keywords are selected when the minimum number of occurrences of a keyword is set as 5, shown in Figure 15.

Similarly, a node with a color represents a keyword in a cluster, and the bigger the node is, the more citations the keyword has. A link between two nodes means the co-occurrence of two keywords, and the thicker the line is, the more co-occurred times they have. In Figure 15, "systems", "algorithm", "membrane computing", "networks" and "machine learning" are highlight in each cluster. In order to understand the characteristic of each cluster, we describe a cluster visualization of keywords in IJCCC by CiteSpace, shown in Figure 16. When the minimum number of citations of a keyword is set as 10, 11 associated clusters are summarized among totally 34 clusters according to all keywords of publications in IJCCC. To be specific, the clusters are "fuzzy control", "routing", "citation of books", "wireless sensor networks", "Dempster-Shafer evidence theory", "forest policy", "membrane computing", "semantic web", "system development life circle model", "machine learning", "knowledge management" and "petri nets" in order. 
Bibliometric Analysis on Research Trends of

Table 7: The top 12 cited journals with the strongest citation bursts from 2006 to 2019

\begin{tabular}{|c|c|c|c|c|c|c|}
\hline Rank & Cited Authors & Year & Strength & Begin & End & $2006-2019$ \\
\hline 1 & LECT NOTES COMPUTER & 2006 & 8.6363 & 2006 & 2010 & \\
\hline 2 & $\begin{array}{l}\text { MEMBRANE COMPUT- } \\
\text { ING I }\end{array}$ & 2006 & 8.0721 & 2009 & 2010 & \\
\hline 3 & IEEE ACM T NETWORK & 2006 & 5.0765 & 2011 & 2015 & \\
\hline 4 & COMPUT COMMUN & 2006 & 5.0340 & 2012 & 2013 & \\
\hline 5 & IEEE T NEURAL NETWOR & 2006 & 4.9156 & 2010 & 2013 & \\
\hline 6 & J PROCESS CONTR & 2006 & 4.0303 & 2007 & 2008 & \\
\hline 7 & IEEE INFOCOM SER & 2006 & 3.9476 & 2012 & 2016 & \\
\hline 8 & IEEE COMMUN LETT & 2006 & 3.8981 & 2011 & 2014 & \\
\hline 9 & THEOR COMPUT SCI & 2006 & 3.7852 & 2006 & 2011 & \\
\hline 10 & $\begin{array}{l}\text { INT J COMPUTERS } \\
\text { COMM }\end{array}$ & 2006 & 3.5514 & 2007 & 2008 & \\
\hline 11 & WIREL NETW & 2006 & 3.5024 & 2011 & 2012 & \\
\hline 12 & LECT NOTES ARTIF INT & 2006 & 3.3479 & 2008 & 2011 & \\
\hline
\end{tabular}




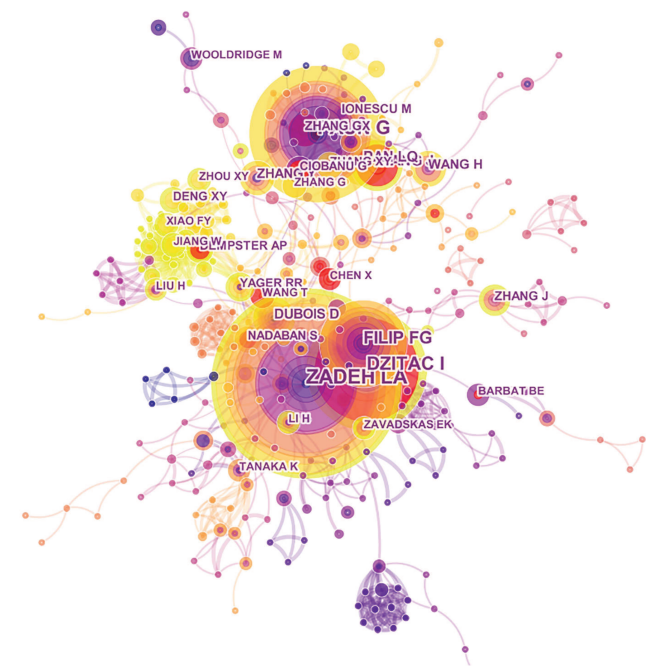

(a)

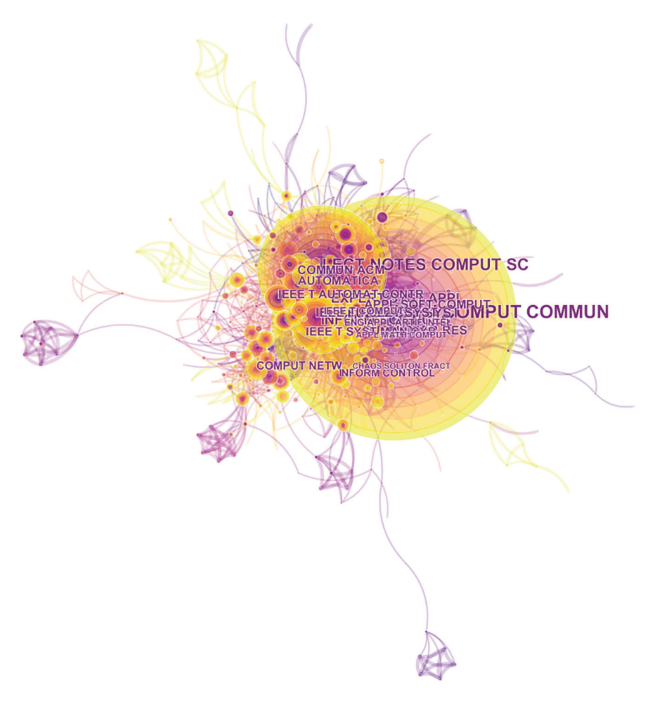

(b)

Figure 13: Co-citation networks at level of authors and journals in IJCCC: (a) Authors' cocitation network (b) Journals' co-citation network

Table 8: The top 2 cited references with the strongest citation bursts from 2006 to 2019

\begin{tabular}{|l|l|l|l|l|l|l|}
\hline Rank & Reference & Year & Strength Begin & End & $2006-2019$ \\
\hline 1 & $\begin{array}{l}\text { PAUN G, MEMBRANE } \\
\text { COMPUTING I }\end{array}$ & 2000 & $\mathbf{7 . 6 0 2 2}$ & 2009 & 2010 & \\
\hline 2 & $\begin{array}{l}\text { DZITAC I, INT J COMPUT } \\
\text { COMMUN }\end{array}$ & 2009 & $\mathbf{5 . 8 1 4 4}$ & 2009 & 2010 & \\
\hline
\end{tabular}

In order to depict the trend of the keywords of publications in IJCCC from 2006 to 2019, Figure 17 shows the timeline view of keywords by CiteSpace. Five stages are presented during the whole time period. Firstly, it focused more on "architecture", "genetic algorithm", and "multiagent system" between 2006 and 2007. Secondly, the keywords of "combinational optimization", "fuzzy set", "fuzzy logic" and "human-computer interaction" occurred most from 2007 to 2010. Next, it paid more attention to "adaptive control", "performance analysis", "sensor networks" and "machine learning" between 2010 and 2013. Then, the publications preferred to occur keywords like "space", "priority", "similarity measure" and "multidimensional scaling" from 2013 to 2016. Finally, the publications have focused more on "group decision making", "big data model", "representation" and "dependence assessment" in recent four years. Over time, the keywords of publications in IJCCC have changed continually, and IJCCC has focused more on fuzzy group decision making in the fields of automation control systems and computer science in the age of big data. 
Bibliometric Analysis on Research Trends of

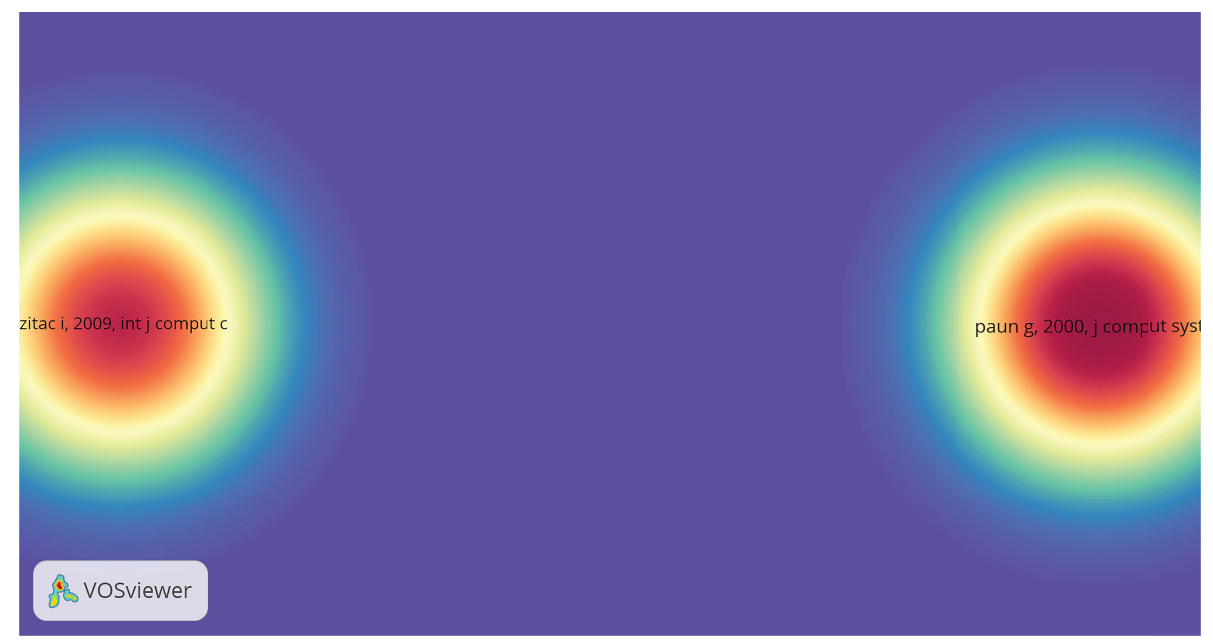

Figure 14: Co-citation density visualization of references in IJCCC

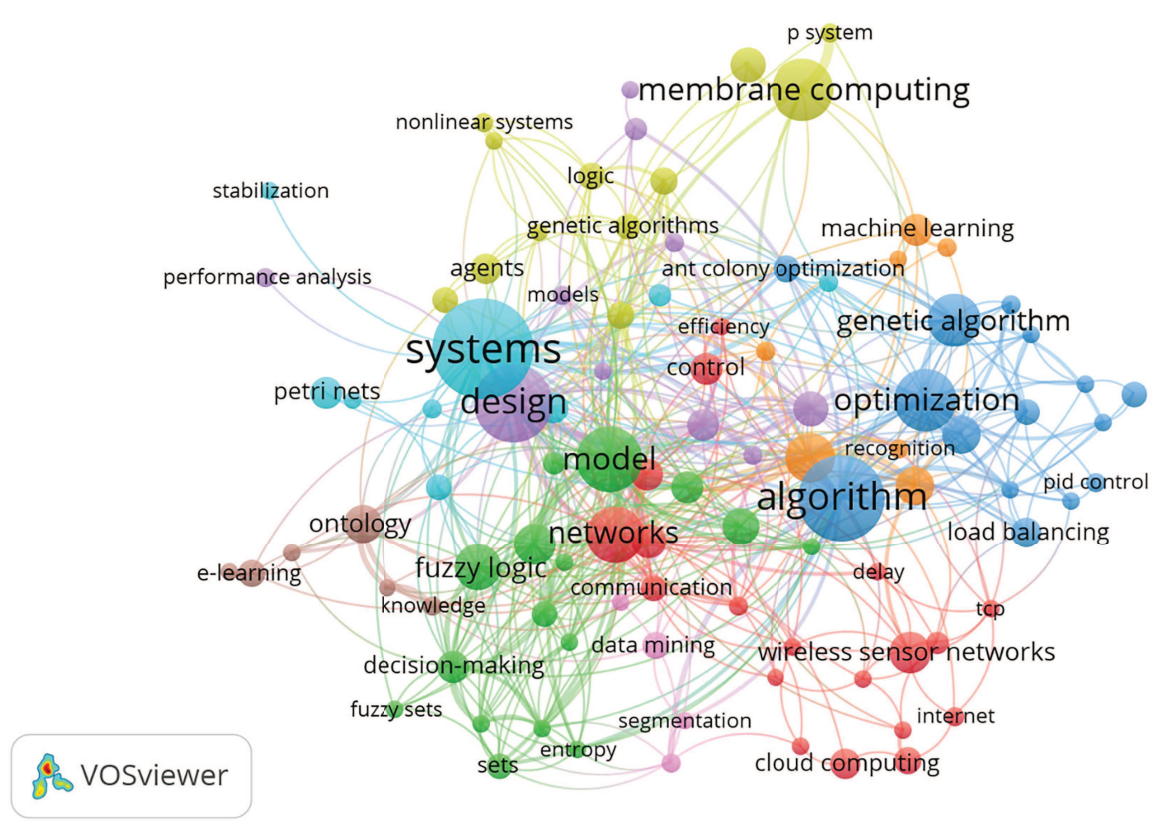

Figure 15: The keyword co-occurrence network of publications in IJCCC 


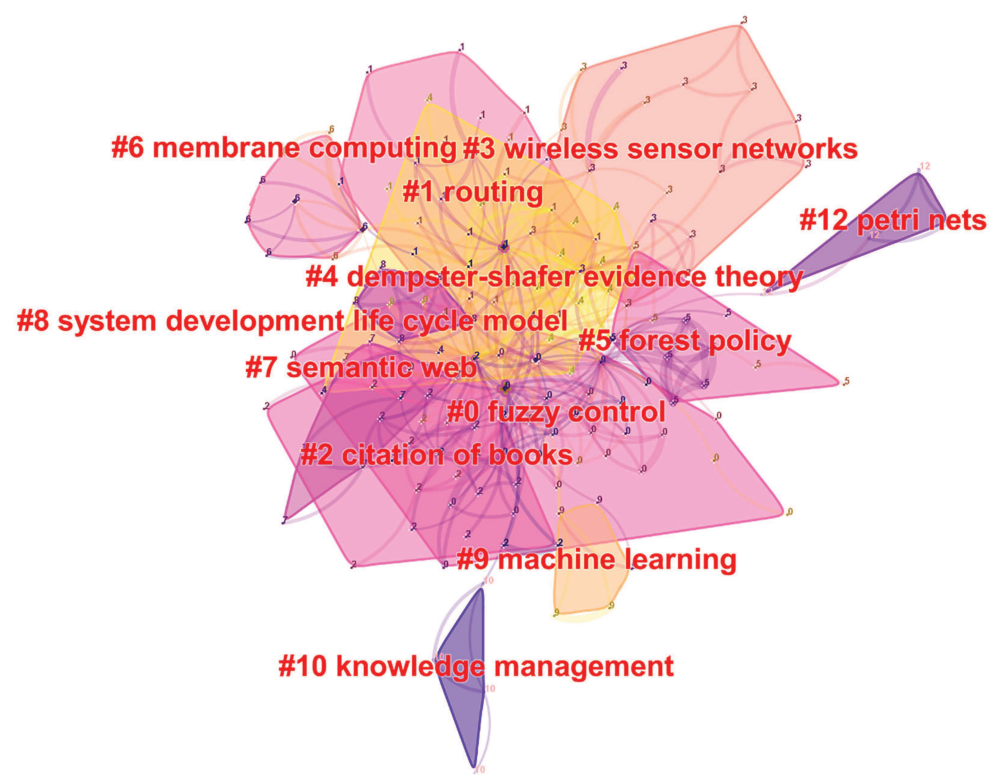

Figure 16: The cluster visualization of keywords in IJCCC

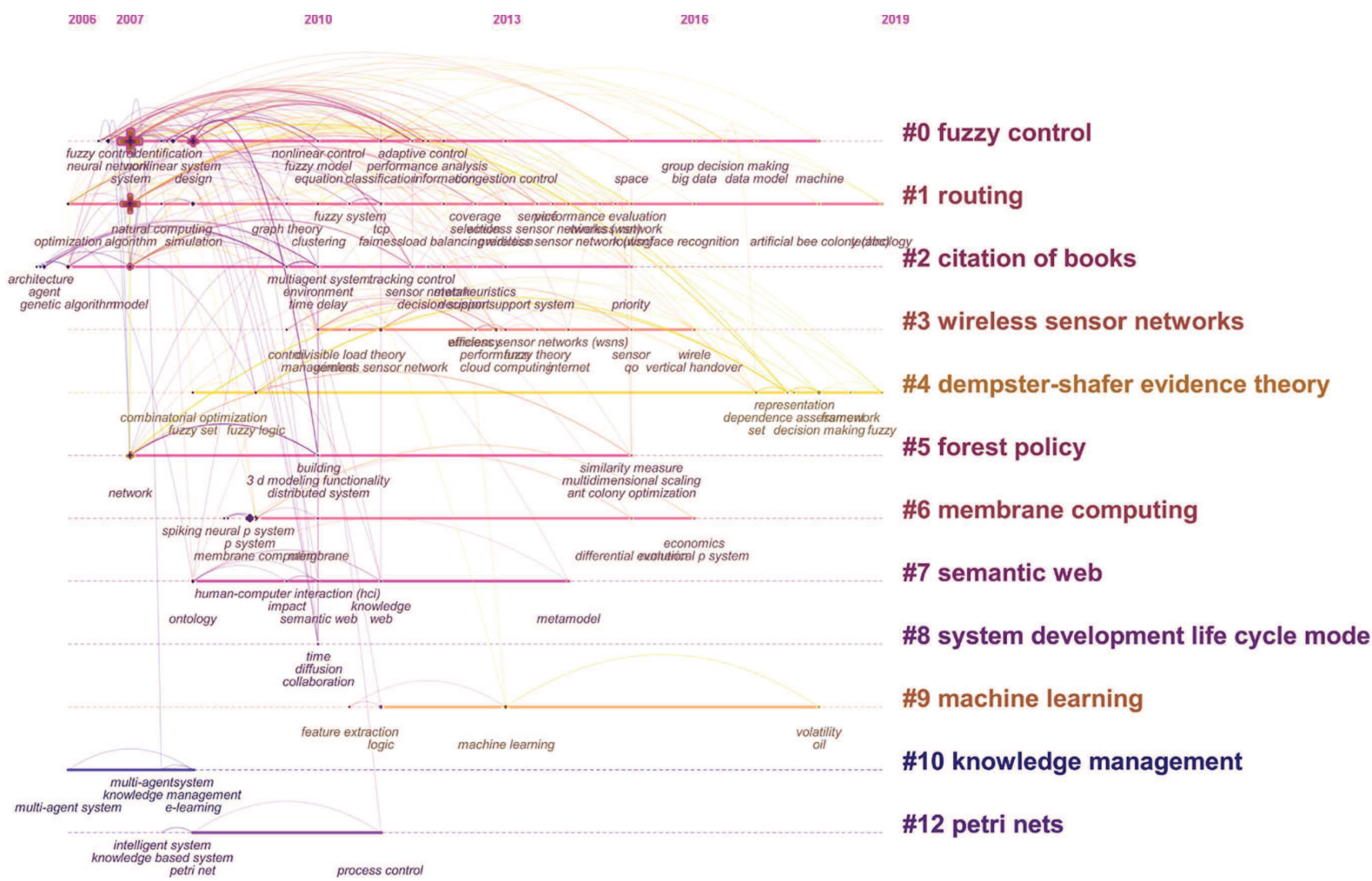

Figure 17: The timeline view of keywords in $I J C C C$ 


\section{Discussion}

International Journal of Computers Communications \& Control has contributed to the fields of automation control systems and computer science since 2006. According to analysis results about fundamental information of publications, characteristics of countries/regions, institutions and authors, and landscape view, we give some discussions about current challenges and possible research trends of $I J C C C$.

(1) Since the number of publications has been steady during the last decade, IJCCC has a certain requirement about theme and quality of publications. Considering the number of citations, the trend increases from 2006 to 2008, and has a certain fluctuation between 2009 and 2015 , which indicates that $I J C C C$ has created the influence in the relative fields. Besides, half of the top 10 cited publications are related to fuzzy theory, which represents that the research in $I J C C C$ does well in fuzzy logic and fuzzy information applied to computers, communications and control.

(2) According to characteristics of countries/regions, institutions and authors, most countries/regions are from East Europe, East Asia and South Asia. In addition, 9 institutions are all from Romania and one from China in the top 10 prolific institutions, and four authors from Romania in the top 10 prolific authors, followed by Chile. Therefore, it is an opportunity and challenge for IJCCC to increase scientific influence so that authors and institutions from other countries/regions prefer to publish relative documents in the journal.

(3) On the basis of landscape analysis, we further discuss some interesting phenomena. Institutions and authors are not obvious in the co-authorship networks, and their hotspots are relatively sparse in the density visualization of bibliographic coupling analysis, where the same situation exists at level of countries/regions, expect for Romania and China. It may be a good way for IJCCC to develop scientific research by international communication and cooperation with various institutions and authors. In burst detection analysis, there are only two cited references with strongest citation bursts, which indicates that there is a development space for $I J C C C$ to increase the attention among academic journals. In terms of co-occurrence analysis and timeline view analysis, the trend of hot topics in IJCCC has turned to group decision making and big data model under complex and uncertain environment. Therefore, International Journal of Computers Communications \& Control provides an important and valuable platform for scholars to research decision making methods and big data model of automation control systems and computer science.

\section{Conclusions}

This paper studies research trends of International Journal of Computers Communications \& Control from 2006 to 2019 by performing bibliometric analysis. Depending on data from WoS, the work is conducted by VoS viewer and CiteSpace from three aspects, which are fundamental information of publications, characteristics of countries/regions, institutions and authors, and landscape analysis. Specifically, type, annual trend and the most cited publications are explored in $I J C C C$, and the number of publications has almost been steady since 2009. Romanian is the most prolific and influential country, and publications from Spain has the highest citations per year. The top 3 prolific institutions are BABES BOLYAI UNIVERSITY, UNIVERSITY OF ORADEA and LUCIAN BLAGA UNIVERSITY OF SIBIU, respectively. DZITAC I. (Romanian) is the most prolific author, followed by DONOSO Y. (Colombia) and BORNE P. (France). Landscape analysis is presented including co-authorship analysis, bibliographic coupling analysis, co-citation and burst detection analysis, co-occurrence and timeline view analysis. Furthermore, we discuss the current challenges and possible research trends according to the above- 
mentioned analysis. The work is valuable for scholars to understand the trend and grasp hot topics related to automation control systems and computer science. In the future, we will further study bibliometric methods in depth and focus on the development of International Journal of Computers Communications \& Control.

\section{Acknowledgments}

The work was supported by the National Natural Science Foundation of China (Nos. 71571123, 71771155 and 71801174$)$.

\section{Bibliography}

[1] Andonie, R. ; Dzitac, I. (2010). How to Write a Good Paper in Computer Science and How Will It Be Measured by ISI Web of Knowledge, International Journal of Computers Communications \& Control, 5(4), 432-446, 2010.

[2] Azevedo, S. G.; Santos, M.; Antón, J. R. (2019). Supply chain of renewable energy: A bibliometric review approach, Biomass and Bioenergy, 70-83, 2019.

[3] Chan, T. M.; Kuehl, D. R. (2019). On lampposts, sneetches, and stars: a call to go beyond bibliometrics for determining academic value, Academic Emergency Medicine, 688-694, 2019.

[4] Chen, C. M. (2006). CiteSpace II: Detecting and visualizing emerging trends and transient patterns in scientific literature, Journal of the American Society for Information Science and Technology, 359-377, 2006.

[5] Cobo, M. J.; Lopez-Herrera, A. G.; Herrera-Viedma, E.; Herrera, F. (2011). Science mapping software tools: Review, analysis, and cooperative sudy among tools, Journal of the American Society for Information Science and Technology, 1382-1402, 2011.

[6] Falagas, M. E.; Pitsouni, E. I.; Malietzis, G. A.; Pappas, G. (2008). Comparison of PubMed, Scopus, Web of Science, and Google Scholar: strengths and weaknesses, Faseb Journal, 338$342,2008$.

[7] Hache, E.; Palle, A. (2019). Renewable energy source integration into power networks, research trends and policy implications: A bibliometric and research actors survey analysis, Energy Policy, 23-35, 2019.

[8] He, X. R.; Wu, Y. Y.; Yu, D. J.; Merigo, J. M. (2017). Exploring the ordered weighted averaging operator knowledge domain: A bibliometric analysis, International Journal of Intelligent Systems, 1151-1166, 2017.

[9] Heersmink, R.; Van den Hoven, J.; Van Eck, N. J.; Van den Berg, J. (2011). Bibliometric mapping of computer and information ethics, Ethics and Information Technology, 241-249, 2011.

[10] Hsieh, P. N.; Chang, P. L. (2009). An assessment of word-wide research productiveity in production and operations management, International Journal of Production Economics, 540-551, 2009.

[11] Jiang, W.; Yang, Y.; Luo, Y.; Qin, X. Y. (2015). Determining basic probability assignment based on the improved similarity measures of generalized fuzzy numbers, International Journal of Computers Communications and Control, 333-347, 2015. 
[12] Kamdem, J. P.; Duarte, A. E.; Lima, K. R. R.; Rocha, J. B. T.; Hassan, W.; Barros, L. M.; Roeder, T.; Tsopmo, A. (2019). Research trends in food chemistry: A bibliometric review of its 40 years aniversary (1976-2016), Food Chemistry, 448-457, 2019.

[13] Keshavarz Ghorabaee, M.; Zavadskas, E. K.; Amiri, M.; Turskis, Z. (2016). Extended EDAS method for fuzzy multi-criteria decision-making: An application to supplier selection, International Journal of Computers Communications and Control, 358-371, 2016.

[14] Laengle, S.; Merigo, J. M.; Miranda, J.; Slowinski, R.; Bomze, I.; Borgonovo, E.; Dyson, R.G.; Oliveira, J. F.; Teunter, R. (2017). Forty years of the European Journal of Operational Research: A bibliometric overview, European Journal of Operational Research, 803-816, 2017.

[15] Li, Y.; Deng, Y. (2018). Generalized ordered propositions fusion based on belief entropy, International Journal of Computers Communications and Control, 792-807, 2018.

[16] Liu, W. S.; Liao, H. C. (2017). A bibliometric analysis of fuzzy decision research during 1970-2015, International Journal of Fuzzy Systems, 1-14, 2017.

[17] Maditati, D. R.; Munim, Z. H.; Schramm, H. J.; Kummer, S. (2018). A review of green supply chain management: From bibliometric analysis to a conceptual framework and future research directions, Resources Conservation and Recycling, 150-162, 2018.

[18] Pilkington, A.; Meredith, J. (2009). The evolution of the intellectual structure of operations management-1980-2006: A citation/co-citation analysis, Journal of Operational Management, 185-202, 2009.

[19] Pinto, M. (2015). Viewing and exploring the subject area of information literacy assessment in higher education (2000-2011), Scientometrics, 227-245, 2015.

[20] Precup, R. E.; Tomescu, M. L.; Preitl, S. (2009). Fuzzy logic control system stability analysis based on lyapunov's direct method, International Journal of Computers Communications and Control, 415-426, 2009.

[21] Shang, G. Z.; Saladin, B.; Fry, T.; Donohue, J. (2015). Twenty-six years of operations management research (1985-2010): authorship patterns and research constituents in eleven top rated journals, International Journal of Production Research, 6161-6197, 2015.

[22] Stopar, K.; Bartol, T. (2019). Digital competences, computer skills and information literacy in secondary education: mapping and visualization of trends and concepts, Scientometrics, 479-498, 2019.

[23] Turskis, Z.; Zavadskas, E. K.; Antucheviciene, J.; Kosareva, N. (2015). A hybrid model based on fuzzy AHP and fuzzy WASPAS for construction site selection, International Journal of Computers Communications and Control, 873-888, 2015.

[24] Wang, X. X.; Xu, Z. S.; Gou, X. J. (2019). Nested probabilistic-numerical linguistic term sets in two-stage multi-attribute group decision making, Applied Intelligence, 2582-2602, 2019 .

[25] Wang, X. X.; Xu, Z. S.; Gou, X. J.; Trajkovic, L. (2019). Tracking a maneuvering target by multiple sensors using extended kalman filter with nested probabilistic-numerical linguistic information, IEEE Transaction on Fuzzy Systems, DOI: 10.1109/TFUZZ. 2019.2906577. 
[26] Wang, X. X.; Xu, Z. S.; Gou, X. J; Xu, M. (2019). Distance and similarity measures for nested probabilistic-numerical linguistic term sets applied to evaluation of medical treatment, International Journal of Fuzzy Systems, 1306-1329, 2019.

[27] White, H. (2018). Pennants for Garfield: bibliometrics and document retrieval, Scientometrics, 757-778, 2018.

[28] Yu, D. J.; Xu, Z. S.; Kao, Y. S.; Lin, C. T. (2018). The structure and citation landscape of IEEE Transactions on Fuzzy Systems (1994-2015), IEEE Transactions on Fuzzy Systems, 430-442, 2018.

[29] Yu, D. J.; Xu, Z. S.; Pedrycz, W.; Wang, W. R. (2017). Information sciences 1968-2016: A retrospective analysis with text mining and bibliometric, Information Sciences, 619-634, 2017.

[30] Yu, D. J.; Xu, Z. S.; Saparauskas, J. (2019). The evolution of "Technological and Economic Development of Economy": a bibliometric analysis, Technological and Economic Development of Economy, 369-385, 2019.

[31] Yu, D. J.; Xu, Z. S.; Wang, W. R. (2018). Bibliometric analysis of fuzzy theory research in China: A 30-year perspective, Knowledge-Based Systems, 188-199, 2018.

[32] http://univagora.ro/jour/index.php/ijccc/. 